Pacific Journal of Mathematics

ON THE REGIONS BOUNDED BY HOMOTOPIC CURVES 


\title{
ON THE REGIONS BOUNDED BY HOMOTOPIC CURVES
}

\author{
A. MARDEN ${ }^{1}$, I. RICHARDS ${ }^{2}$, AND B. RODIN ${ }^{3}$
}

We give a short proof of the following theorem of $H . I$. Levine [2]:

Let $\mathscr{A}$ and $\mathscr{B}$ be nonintersecting simple closed curves on an orientable surface $S$ (compact or not).

(i) If $\mathscr{A}$ is homotopic to zero, then $\mathscr{A}$ bounds a closed disk in $S$.

(ii) If $\mathscr{A}$ and $\mathscr{B}$ are freely homotopic but not homotopic to zero then $\mathscr{A} \cup \mathscr{B}$ bounds a closed cylinder in $S$.

The proof is based on some elementary properties of covering surfaces and the Jordan-Schönflies Theorem for planar surfaces and is as follows. Let $H$ be the cyclic subgroup of $\pi_{1}(S)$ generated by $\mathscr{A}$. By a standard construction (see [1]) we may form a covering surface $\widetilde{S} \stackrel{\pi}{\longrightarrow} S$ of $S$ having the following properties: (1) $\pi_{1}(\widetilde{S}) \approx H$; (2) we distinguish a point $O \in S$ and a point $\widetilde{O} \in \widetilde{S}$ lying over $O$-then if $\mathscr{D}$ is a closed curve in $S$ through $O$ and $\tilde{\mathscr{D}}$ is the lift of $\mathscr{D}$ to $\widetilde{S}$ which passes through $\widetilde{O}$, the curve $\widetilde{\mathscr{D}}$ is closed in $\widetilde{S}$ if and only if $\mathscr{D} \in H$.

There exist closed curves $\widetilde{\mathscr{A}}_{1}$ and $\widetilde{\mathscr{B}}_{1}$ in $\widetilde{S}$ which are lifts of $\mathscr{A}$ and $\mathscr{B}$. To see this assume that $O \in \mathscr{A}$ so by (2) $\mathscr{A}$ lifts to a closed curve through $\widetilde{O}$. Since $\mathscr{A}$ and $\mathscr{B}$ are freely homotopic there is an arc $\gamma$ from $\mathscr{A}$ to $\mathscr{B}$ such that $\mathscr{A} \sim \gamma \mathscr{B} \gamma^{-1}$. Then $\gamma \mathscr{B} \gamma^{-1}$ has at least one lift to a closed curve in $\widetilde{S}$; hence so does $\mathscr{B}$.

LEMMA. If $\widetilde{R}$ is a compact region in $\widetilde{S}, \pi$ is one-to-one on $\partial \widetilde{R}$, and $\pi$ (int $\widetilde{R}) \cap \pi(\partial \widetilde{R})=\varnothing$, then $\pi$ maps $\widetilde{R}$ homeomorphically onto $\pi(\widetilde{R})$.

Proof. The hypotheses imply that the region $\widetilde{R}_{0} \equiv \operatorname{int} \widetilde{R}$ is an unlimited covering surface of $\pi\left(\widetilde{R}_{0}\right)$. We show that every point of $\pi\left(\widetilde{R}_{0}\right)$ is covered exactly once. For suppose $\widetilde{p}_{1}, \widetilde{p}_{2}$ are two points over $p \in \pi\left(\widetilde{R}_{0}\right)$. Let $\gamma$ be an arc in $\pi\left(\widetilde{R}_{0}\right)$ from $p$ to $\pi(\partial \widetilde{R})$ and let $\widetilde{\gamma}_{1}, \widetilde{\gamma}_{2}$, be arcs over $\gamma$ from $\widetilde{p}_{1}$ and $\widetilde{p}_{2}$. Then by our hypotheses $\widetilde{\gamma}_{1}$ and $\widetilde{\gamma}_{2}$ must intersect on $\partial \widetilde{R}$, and the trivial curve $\gamma-\gamma$ in $S$ lifts to the curve $\tilde{\gamma}_{1}-\widetilde{\gamma}_{2}$ in $\widetilde{S}$, a contradiction.

To prove (i) above, we may assume that $\widetilde{S}$, the universal covering surface of $S$, is a disk. Since $\mathscr{A} \sim 1$, every lift of $\mathscr{A}$ to $\widetilde{S}$ is a

1 Partially supported by the National Science Foundation (GP-2280)

2 Partially supported by the National Science Foundation (G-24295)

3 Partially supported by the Office of Naval Research Contract Nonr 710 (54). 
closed curve in $\widetilde{S}$ (monodromy theorem). The points in $\widetilde{S}$ over a point $p \in S$ have no limit point in $\widetilde{S}$; hence there must exist at least one arc $\tilde{\mathscr{A}}_{0}$ lying above $\mathscr{A}$ and bounding a region $\widetilde{R}$ whose interior contains no points lying over $\mathscr{A} . \quad \widetilde{R}$ is a topological disk (JordanSchönflies), and the above lemma implies that $\mathscr{A}$ bounds the region $\pi(\widetilde{R})$ which is homeomorphic to $\widetilde{R}$. This proves (i).

The proof of (ii) is achieved through the following steps.

$1^{\circ} . \quad \widetilde{S}$ is a cylinder which we realize as the open plane region bounded by the circles $C_{1}=\{|z|=1\}$ and $C_{2}=\{|z|=2\}$. Indeed, $\pi_{1}(\widetilde{S})$ is cyclic, $\widetilde{S}$ is orientable, and hence $\widetilde{S}$ has genus zero $\left(H_{1}(\widetilde{S})\right.$ has no nonzero intersections). Thus $\widetilde{S}$ may be imbedded in $\mathbf{R}^{2}$; since $H_{1}(\widetilde{S})$ is cyclic and not zero, $\widetilde{S}$ is a cylinder.

$2^{\circ}$. If $\mathscr{A} \nsim 1$ in $S$, then $\mathscr{A}^{n} \nsim 1$ for all $n$. For $\mathscr{A}$ lifts to a closed curve $\tilde{\mathscr{A}_{1}} \nsim 1$ in the cylinder $\widetilde{S}$ (otherwise $\mathscr{A} \sim 1$ ); if $\mathscr{A}^{n} \sim 1$, then $\widetilde{\mathscr{A}_{1}^{n}} \sim 1$ which is impossible since the cylinder has no torsion.

$3^{\circ}$. If $\tilde{\mathscr{A}}$ is any lift of $\mathscr{A}$ in $\tilde{S}$ then either $\tilde{\mathscr{A}}$ is a simple closed curve which separates $C_{1}$ and $C_{2}$ or the corresponding lift $\tilde{A}^{n}$ of $\mathscr{A}^{n}$ is not closed in $\widetilde{S}$ for any $n$. Any pair of closed lifts of $\mathscr{A}$ and/or $\mathscr{B}$ lie one inside the other with respect to the fixed imbedding of $\widetilde{S} \subset \mathbf{R}^{2}$.

For the proof, suppose that for some $n, \mathscr{A}^{n}$ is a simple closed curve. Then by the Jordan-Schönflies Theorem, $\tilde{\mathscr{A}}^{n}$ is homotopic either to $\tilde{\mathscr{A}}_{1}$ (the fixed closed lift of $\mathscr{A}$ in $\widetilde{S}$ ) or to 1 . Since freely homotopic curves in $\widetilde{S}$ project to freely homotopic curves in $S$, we then have $\mathscr{A}^{n-1} \sim 1$ or $\mathscr{A}^{n} \sim 1$ respectively; by $2^{\circ}$, we see that $n=1$ and $\tilde{\mathscr{A}} \approx 1$. $\tilde{\mathscr{A}}$ separates $C_{1}$ and $C_{2}$ since, for any connected set $\Gamma$ such that $\Gamma \cap C_{1}, \Gamma \cap C_{2} \neq \varnothing, S-\Gamma$ is simply connected. Given any pair of disjoint simple closed curves which separate $C_{1}$ and $C_{2}$, the one which first meets the cross cut $\{1 \leqq x \leqq 2\}$ lies inside the other one.

$4^{\circ}$. There are at most a finite number of lifts (closed or not) of

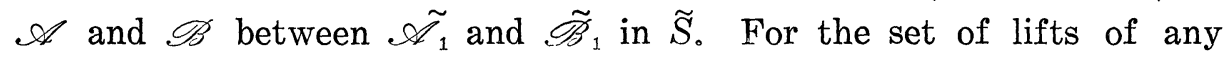
point of $S$ can have no accumulation point in the compact region bounded by $\tilde{\mathscr{A}_{1}}$ and $\tilde{\mathscr{B}}$.

To finish the proof of (ii), we observe that by $3^{\circ}$ and $4^{\circ}$ any lift of $\mathscr{A}$ or $\mathscr{B}$ which lies between $\widetilde{\mathscr{A}}_{1}$ and $\widetilde{\mathscr{B}}_{1}$ in $\widetilde{S}$ must be closed, and there are at most a finite number of such lifts. Hence there 
must be an adjacent pair $\tilde{\mathscr{A}_{p}}, \widetilde{\mathscr{B}_{q}}$. The compact region $\widetilde{R}$ bounded by $\tilde{\mathscr{A}}_{p}$ and $\tilde{\mathscr{B}}_{q}$ is a topological cylinder (Jordan-Schönflies). The above lemma implies that $\pi$ maps $\widetilde{R}$ homeomorphically onto $\pi(\widetilde{R})$, and the proof is complete.

REMARK. In the case (i) an alternative proof can be given based on the fact that the cover transformations of $\widetilde{S}$ over $S$ have no fixed points. In fact it follows easily from the Brouwer Theorem and the fact that the cover transformations are homeomorphisms that the compact regions bounded by the curves $\tilde{A}_{i}$ over $\mathscr{A}$ are disjoint. The proof of (i) then follows by applying the above lemma to any one of these regions.

Finally we wish to point out that the following somewhat more general theorem can be proved by methods entirely analogous to those used above.

THEOREM. Let $\mathscr{A}$ and $\mathscr{B}$ be nonintersecting simple closed curves in an orientable surface $S$ (which we represent as a Riemann surface) such that $\mathscr{A}^{n} \sim \mathscr{B}^{m}$ for some positive integers $m, n$, but $\mathscr{A} \nsim 1$. Then $m=n, \mathscr{A} \sim \mathscr{B}$, and $\mathscr{A}-\mathscr{B}$ is the boundary of a closed cylinder in $S$.

We give a very brief outline of the proof. Let $\widetilde{S}$ be the covering surface of $S$ generated by $\mathscr{A}^{n}$. It follows from the unique continuation property that two closed lifts of $\mathscr{A}^{n}$ cannot intersect in $\widetilde{S}$ unless they coincide. Hence exactly as above we can find a compact cylinder $\widetilde{R}$ in $\widetilde{S}$ bounded by a lift $\tilde{\mathscr{A}}^{n}$ of $\mathscr{A}^{n}$ and a lift $\tilde{\mathscr{B}}^{m}$ or $\mathscr{B}^{m}$ such that no point in the interior of $\widetilde{R}$ lies over $\mathscr{A}$ or $\mathscr{B}$. Setting $R=$ $\pi(\widetilde{R})$, fairly straightforward topological reasoning shows that $R$ is bounded by $\mathscr{A}$ and $\mathscr{B}$ and that the interior of $\widetilde{R}$ is a smooth unlimited covering surface of int $(R)$, which each point in int $(R)$ covered the same number of times. In particular, this shows that $m=n$. Since the interior of $\widetilde{R}$ is an $n$-sheeted covering surface of int $(R)$, the fundamental group of $\operatorname{int}(\widetilde{R})$ is naturally isomorphic to a subgroup of index $n$ of the group $\pi_{1}(\operatorname{int}(R))$. Since $\pi_{1}(\operatorname{int}(\widetilde{R}))$ is infinite cyclic and $\pi_{1}(\operatorname{int}(R))$ has no torsion, it follows that $\pi_{1}(\operatorname{int}(R))$ is a cyclic group and hence that $\operatorname{int}(R)$ is a topological cylinder. Finally, the fact that $R$ is a closed cylinder bounded by the Jordan curves $\mathscr{A}$ and $\mathscr{B}$ may be proved by fairly standard conformal mapping arguments.

\section{BIBLIOGRAPHY}

1. P. J. Hilton and S. Wylie, Homology Theory, Cambridge University Press, Cambridge, 1960 .

2. H. I. Levine, Homotopic curves on surfaces, Proc. Amer. Math. Soc. 14 (1963), 986-990. 



\section{PACIFIC JOURNAL OF MATHEMATICS}

\section{EDITORS}

\section{H. SAMELSON}

Stanford University

Stanford, California

\section{R. M. BLUMenthaL \\ University of Washington \\ Seattle, Washington 98105}

*J. DugundjI

University of Southern California Los Angeles, California 90007

\section{RICHARD ARENS}

University of California

Los Angeles, California 90024

\section{ASSOCIATE EDITORS}
E. F. BECKENBACH
B. H. NeUManN
F. WOLF
K. YosIDA

\section{SUPPORTING INSTITUTIONS}

\author{
UNIVERSITY OF BRITISH COLUMBIA \\ CALIFORNIA INSTITUTE OF TECHNOLOGY \\ UNIVERSITY OF CALIFORNIA \\ MONTANA STATE UNIVERSITY \\ UNIVERSITY OF NEVADA \\ NEW MEXICO STATE UNIVERSITY \\ OREGON STATE UNIVERSITY \\ UNIVERSITY OF OREGON \\ OSAKA UNIVERSITY \\ UNIVERSITY OF SOUTHERN CALIFORNIA
}

\author{
STANFORD UNIVERSITY \\ UNIVERSITY OF TOKYO \\ UNIVERSITY OF UTAH \\ WASHINGTON STATE UNIVERSITY \\ UNIVERSITY OF WASHINGTON \\ AMERICAN MATHEMATICAL SOCIETY \\ CHEVRON RESEARCH CORPORATION \\ TRW SYSTEMS \\ NAVAL ORDNANCE TEST STATION
}

Mathematical papers intended for publication in the Pacific Journal of Mathematics should be typewritten (double spaced). The first paragraph or two must be capable of being used separately as a synopsis of the entire paper. It should not contain references to the bibliography. Manuscripts may be sent to any one of the four editors. All other communications to the editors should be addressed to the managing editor, Richard Arens at the University of California, Los Angeles, California 90024.

50 reprints per author of each article are furnished free of charge; additional copies may be obtained at cost in multiples of 50 .

The Pacific Journal of Mathematics is published monthly. Effective with Volume 16 the price per volume (3 numbers) is $\$ 8.00$; single issues, $\$ 3.00$. Special price for current issues to individual faculty members of supporting institutions and to individual members of the American Mathematical Society: $\$ 4.00$ per volume; single issues $\$ 1.50$. Back numbers are available.

Subscriptions, orders for back numbers, and changes of address should be sent to Pacific Journal of Mathematics, 103 Highland Boulevard, Berkeley 8, California.

Printed at Kokusai Bunken Insatsusha (International Academic Printing Co., Ltd.), No. 6, 2-chome, Fujimi-cho, Chiyoda-ku, Tokyo, Japan.

PUBLISHED BY PACIFIC JOURNAL OF MATHEMATICS, A NON-PROFIT CORPORATION

The Supporting Institutions listed above contribute to the cost of publication of this Journal, but they are not owners or publishers and have no responsibility for its content or policies.

* Paul A. White, Acting Editor until J. Dugundji returns. 


\section{Pacific Journal of Mathematics}

\section{Vol. 16, No. 2 December, 1966}

Loren N. Argabright, Invariant means on topological semigroups ........ 193

William Arveson, A theorem on the action of abelian unitary groups ...... 205

John Spurgeon Bradley, Adjoint quasi-differential operators of Euler

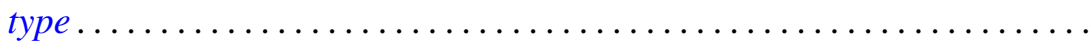

Don Deckard and Lincoln Kearney Durst, Unique factorization in power series rings and semigroups ........................... 239

Allen Devinatz, The deficiency index of ordinary self-adjoint differential operators..................................... 243

Robert E. Edwards, Operators commuting with translations ............ 259

Avner Friedman, Differentiability of solutions of ordinary differential equations in Hilbert space .............................. 267

Boris Garfinkel and Gregory Thomas McAllister, Jr., Singularities in a variational problem with an inequality ......................

Seymour Ginsburg and Edwin Spanier, Semigroups, Presburger formulas,

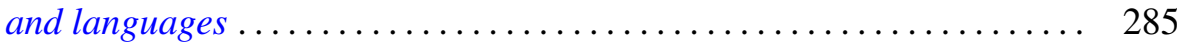

Burrell Washington Helton, Integral equations and product integrals . . . . . . 297

Edgar J. Howard, First and second category Abelian groups with the n-adic topology.........................................

Arthur H. Kruse and Paul William Liebnitz, Jr., An application of a family homotopy extension theorem to ANR spaces.

Albert Marden, I. Richards and Burton Rodin, On the regions bounded by homotopic curves

Willard Miller, Jr., A branching law for the symplectic groups ...

Marc Aristide Rieffel, A characterization of the group algebras of the finite

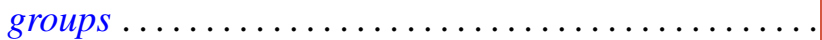

P. P. Saworotnow, On two-sided $H^{*}$-algebras

John Griggs Thompson, Factorizations of p-solvable groups ...

Shih-hsiung Tung, Harnack's inequalities on the classical Cartan

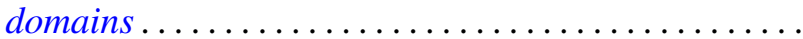

